\title{
P2Y12 inhibitors: do they increase cancer risk?
}

\author{
Joseph J. Fierro ${ }^{1}$, Brandon Cave ${ }^{2}$, Rami N. Khouzam ${ }^{3}$ \\ ${ }^{1}$ Department of Pharmacy, James A. Haley Veterans Hospital, Tampa, FL, USA; ${ }^{2}$ Department of Pharmacy, Methodist University Hospital, \\ Memphis, TN, USA; ${ }^{3}$ Department of Internal Medicine, Division of Cardiovascular Diseases, University of Tennessee Health Science Center, \\ Memphis, TN, USA \\ Contributions: (I) Conception and design: B Cave; (II) Administrative support: RN Khouzam; (III) Provision of study materials or patients: All authors; \\ (IV) Collection and assembly of data: All authors; (V) Data analysis and interpretation: All authors; (VI) Manuscript writing: All authors; (VII) Final \\ approval of manuscript: All authors. \\ Correspondence to: Joseph J. Fierro, PharmD, BCACP. Department of Pharmacy, James A. Haley Veterans Hospital, 13000 Bruce B. Downs Boulevard \\ (119), Tampa, FL 33612, USA. Email: Joseph.Fierro@va.gov.
}

\begin{abstract}
Treatment with dual antiplatelet therapy (DAPT), typically combining a P2Y12 inhibitor with aspirin, is the standard of care for the prevention of coronary stent thrombosis, especially post revascularization and in the setting of acute coronary syndromes (ACS). Determining the appropriate duration has been debated as prolonged courses have been associated with reduced thrombotic complications. Despite proven benefit, there have been reports of a potential cancer risk associated with DAPT following the FDA's review of the TRITON-TIMI 38 trial and the DAPT trial. The latter revealed an increased risk of non-cardiovascular death, which was driven by more bleeding and cancer-related deaths. This further clouds the decision if longer courses of DAPT should be recommended. Several trials and meta-analyses have been conducted to further review this cancer risk with P2Y12 inhibitors. This manuscript intends to evaluate current literature to determine if there is a risk of cancer for patients on DAPT and its consequences in the management of cardiovascular disease.
\end{abstract}

Keywords: Dual antiplatelet therapy (DAPT); dual anti platelet; cancer

Submitted Jul 01, 2019. Accepted for publication Jul 19, 2019.

doi: 10.21037/atm.2019.07.90

View this article at: http://dx.doi.org/10.21037/atm.2019.07.90

\section{Introduction}

Treatment with dual antiplatelet therapy (DAPT), typically a combination of aspirin and a P2Y12 inhibitor, is commonly used for the prevention and treatment of cardiovascular, cerebrovascular and peripheral vascular disease. In particular, DAPT is beneficial in patients undergoing percutaneous coronary intervention (PCI) for acute coronary syndromes (ACS) and stable coronary artery disease for up to 1 year (1). Prolonged DAPT duration has been evaluated hoping to provide a greater benefit on cardiovascular outcomes. The DAPT Study compared the efficacy and safety of prolonged DAPT for 30 months versus 12 months with a thienopyridine after drug-eluting stent placement in patients with ACS (2). Prolonged DAPT reduced the rates of stent thrombosis and major adverse cardiovascular and cerebrovascular events, but with an increase in moderate or severe GUSTO-defined bleeding. Unexpectedly, prolonged DAPT treatment resulted in a higher incidence of all-cause mortality; however, this outcome was driven primarily by non-cardiovascular causes. Among the deaths, a higher incidence of new solid cancers was observed in the prolonged DAPT group $(2.03 \%$ versus $1.62 \%, \mathrm{P}=0.14)$ and a statistically significant increase in cancer-related death $(0.62 \%$ versus $0.28 \%, \mathrm{P}=0.02)$. This conclusion is consistent with the TRITON-TIMI 38 trial which compared the efficacy of six to fifteen months of DAPT using either clopidogrel or prasugrel in patients with moderate to high risk ACS (3). A FDA assessment of this study found roughly a $60 \%$ relative increase in cancer diagnosis $(1.5 \%$ versus $1.0 \% ; \mathrm{P}=0.0013)$ and an numerical increase in cancer-related mortality (4). Similar findings 
were discovered in patients on DAPT regimen containing ticagrelor as the PEGASUS-TIMI 54 trial found statistically significantly higher rates of malignancy-related deaths in the extended courses of ticagrelor $(1.10 \%$ versus $0.76 \%$, $\mathrm{P}=0.034)$ (5). A potential explanation for this finding was an increased likelihood of cancer diagnosis associated with prolonged DAPT therapy. There are relevant hypotheses mechanistically for why this may occur. This review will focus on relevant data to highlight the presence or absence of cancer risk with antiplatelet therapy.

\section{Pharmacology}

Literature has revealed an association between aspirin treatment and a reduction in the incidence of newly diagnosed cancer. The pathological explanation of these findings is based on aspirin's antiplatelet, anti-inflammatory, and proapoptotic effects (6). Contrary to expectations, there are conflicting clinical and laboratory data about the effect of combined aspirin with a P2Y12 inhibitor on cancer incidence, including analyses suggesting an increased cancer risk as mentioned earlier. Some studies have found a possible causal effect, eluding promotion of tumor growth indirectly, increases in metastatic dissemination due to medication-induced platelet aggregation, and possibly decreased ability to keep malignant cancer cells located in situ (7). An increase in cancer diagnosis due to high incidence of bleeding complications in patients on DAPT was also considered. While there are hypotheses as to how this may occur, the evidence remains unclear. This review will focus on relevant data to highlight that the presence or absence of cancer risk with antiplatelet therapy.

\section{P2Y12 inhibition and cancer risk}

Historically, aspirin treatment has been proven to reduce cancer incidence, morbidity and mortality in numerous trials and among a variety of cancers (8). For example, the US Preventive Services Task Force recommends low-dose aspirin for the primary prevention of CVD and colorectal cancer in adults aged $50-59$ years who have a $10 \%$ or greater 10-year CVD risk, and who are not at an increased risk of bleeding, have a life expectancy of at least 10 years, are willing to take aspirin daily for at least 10 years (9). This recommendation was based on several trials that resulted in a reduction of the incidence and mortality of colorectal cancer and other types of solid tumors with aspirin use. The results of clinical and experimental studies support the idea that targeting platelet activation is a promising strategy for cancer prevention. This theory has been challenged with the emergence of conflicting data as mentioned earlier on the effect of DAPT on cancer incidence, even eluding to a potential increase in cancer risk evident by a $30 \%$ increase risk of cancer-related death in patients on prolonged DAPT therapy (2). As a result, further studies reviewing the risk of cancer for patients treated with DAPT, including ticagrelor, have been conducted (see Table 1).

The findings in the DAPT trial led the FDA to conduct a thorough review the evidence. The FDA performed metaanalyses of other trials to assess the effects of clopidogrel on mortality. Their results showed no apparent increase in the risks of cancer-related deaths or cancer-related adverse events with prolonged DAPT with clopidogrel, $0.9 \%$ versus $1.1 \%$, and $4.2 \%$ versus $4 \%$ respectively (10). Other trials since the FDA statement also support this conclusion. Regarding prasugrel, a post-hoc investigation of the TRILOGY-ACS trial to assess participants' cancer history found that the cancer incidence was low overall and similar among patients on prasugrel and clopidogrel (1.8\% versus $1.7 \%, \mathrm{P}=0.79)(11)$. Several other trials, such as CAPRIE, CHARISMA, and PLATO showed no cancer risk with P2Y12 inhibitors (11-14). To further examine any association of cancer with $\mathrm{P} 2 \mathrm{Y} 12$ inhibitors, several cohort trials and meta-analyses have been conducted.

Leader and colleagues conducted a population-based cohort comparing DAPT with clopidogrel, aspirin monotherapy, and no antiplatelet therapy, which found no increased incidence of cancer with DAPT (8). In fact, compared to no antiplatelet therapy, DAPT with clopidogrel was associated with a $54 \%$ reduction in cancer incidence after adjustment for covariates $(11.7 \%$ no antiplatelet drug versus $8.8 \%$ aspirin monotherapy versus $8.5 \%$ DAPT) (8). This result was similar to the findings of an epidemiological investigation in the United Kingdom; which also found no evidence of an increased risk of cancermortality in patients using clopidogrel with concomitant colorectal, breast and prostate cancer (15). Meta-analyses were also conducted to reaffirm this conclusion. Elmariah and colleagues analyzed 6 randomized clinical trials to include over 90,000 patients and found no significant differences in all-cause mortality or cancer between groups (16). Furthermore, a separate analysis of six RCTs and three cohort trials found insufficient evidence to suggest P2Y12 inhibitor exposure with either clopidogrel or prasugrel is associated with increased risk of cancer rate or mortality (17). The largest of such analyses of 14 trials 
Table 1 Review of data associated with no cancer risk with DAPT

\begin{tabular}{|c|c|c|c|c|c|}
\hline Study name/date & Study design & Study methods & $\begin{array}{l}\text { P2Y12 } \\
\text { inhibitor }\end{array}$ & Results & $P$ value \\
\hline \multirow[t]{2}{*}{ FDA analysis; 2014} & \multirow[t]{2}{*}{ Meta-analysis } & \multirow[t]{2}{*}{$\begin{array}{l}\text { Two trial-level meta-analysis } \\
\text { analyzing cancer risk with } \\
\text { clopidogrel treatment }\end{array}$} & \multirow[t]{2}{*}{ Clopidogrel } & $\begin{array}{l}\text { Cancer-adverse events: pDAPT } 4.2 \% \text {; } \\
\text { sDAPT } 4.0 \% \text {; MH RD }=0.19 \%, 95 \% \\
\text { Cl }(-0.2 \% \text { to }-0.59 \%)\end{array}$ & $\begin{array}{l}\text { Not reported } \\
(P>0.05)\end{array}$ \\
\hline & & & & $\begin{array}{l}\text { Cancer related death: pDAPT } 0.9 \% \text {; } \\
\text { sDAPT } 1.1 \% \text {; MH RD }=-0.14 \%, 95 \% \\
\mathrm{Cl}(-0.33 \% \text { to }-0.06 \%)\end{array}$ & $\begin{array}{l}\text { Not reported } \\
(P>0.05)\end{array}$ \\
\hline TRILOGY-ACS; 2016 & $\mathrm{RCT}$ & $\begin{array}{l}\text { Prolonged DAPT with } \\
\text { prasugrel vs. clopidogrel }\end{array}$ & $\begin{array}{l}\text { Clopidogrel, } \\
\text { prasugrel }\end{array}$ & $\begin{array}{l}\text { Cancer incidence: prasugrel } 1.8 \% \text {; } \\
\text { clopidogrel } 1.7 \%\end{array}$ & $P=0.79$ \\
\hline Leader et al., 2017 & Cohort & $\begin{array}{l}\text { DAPT w/clopidogrel vs. } \\
\text { aspirin monotherapy vs. no } \\
\text { antiplatelet }\end{array}$ & Clopidogrel & $\begin{array}{l}\text { Cancer incidence: } 11.7 \% \text { nonuser vs. } \\
8.5 \% \text { DAPT }\end{array}$ & $\mathrm{P}<0.001$ \\
\hline \multirow{2}{*}{ Hicks et al., 2015} & \multirow{2}{*}{ Three Cohorts } & \multirow{2}{*}{$\begin{array}{l}\text { Cohort of (I) colorectal, (II) } \\
\text { breast, (III) prostate cancer } \\
\text { patients with risk of cancer } \\
\text { with clopidogrel }\end{array}$} & \multirow{2}{*}{ Clopidogrel } & $\begin{array}{l}\text { Cancer mortality-2: } 10 \% \text { clopidogrel } \\
\text { vs. } 12 \% \text { nonuser; HR } 1.03\end{array}$ & $P=0.20$ \\
\hline & & & & $\begin{array}{l}\text { Cancer mortality-3: } 11 \% \text { clopidogrel } \\
\text { vs. } 16 \% \text { nonuser; HR } 1.22\end{array}$ & $P=0.87$ \\
\hline \multirow[t]{2}{*}{ Elmariah et al., 2018} & \multirow[t]{2}{*}{ Meta-analysis } & \multirow{2}{*}{$\begin{array}{l}\text { Prolonged DAPT vs. } \\
\text { standard DAPT and no } \\
\text { DAPT with clopidogrel }\end{array}$} & \multirow[t]{2}{*}{ Clopidogrel } & $\begin{array}{l}\text { Cancer incidence }(2.97 \% \text { pDAPT vs. } \\
2.96 \% \text { sDAPT/no DAPT }\end{array}$ & $P>0.99$ \\
\hline & & & & $\begin{array}{l}\text { Cancer related death }(0.93 \% \text { pDAPT } \\
\text { vs. } 0.99 \% \text { sDAPT/no DAPT }\end{array}$ & $P=0.59$ \\
\hline PLATO; 2009 & $\mathrm{RCT}$ & $\begin{array}{l}\text { DAPT with ticagrelor vs. } \\
\text { clopidogrel }\end{array}$ & $\begin{array}{l}\text { Clopidogrel, } \\
\text { ticagrelor }\end{array}$ & $\begin{array}{l}\text { Cancer incidence ( } 1.2 \% \text { ticagrelor vs. } \\
1.3 \% \text { clopidogrel) }\end{array}$ & $P=0.69$ \\
\hline \multirow[t]{2}{*}{$\begin{array}{l}\text { Raposeiras-Roubín } \\
\text { et al., } 2019\end{array}$} & \multirow[t]{2}{*}{ Cohort } & \multirow[t]{2}{*}{$\begin{array}{l}\text { DAPT with clopidogrel vs. } \\
\text { prasugrel vs. clopidogrel }\end{array}$} & \multirow{2}{*}{$\begin{array}{l}\text { Clopidogrel, } \\
\text { prasugrel, } \\
\text { ticagrelor }\end{array}$} & $\begin{array}{l}\text { Cancer risk (sHR } 0.20 \text { ticagrelor vs. } \\
\text { clopidogrel) }\end{array}$ & $P=0.028$ \\
\hline & & & & $\begin{array}{l}\text { Cancer risk (sHR } 0.22 \text { ticagrelor vs. } \\
\text { clopidogrel/prasugrel) }\end{array}$ & $P=0.036$ \\
\hline
\end{tabular}

DAPT, dual antiplatelet therapy; ASA, aspirin; HR, hazard ratio; MH RD, Mantel-Haenszel risk difference; non-user, no antiplatelets; OR, odds ratio; pDAPT, prolonged DAPT; sDAPT, standard DAPT; SHR, subhazard ratio.

found continued DAPT greater than one year was not associated with an increase in all-cause mortality, including non-cardiovascular mortality compared to aspirin alone or shorter duration DAPT (18).

The majority of analyses evaluating DAPT and cancer risk have not included ticagrelor, however animal studies have suggested a potential protective effect. Gebremeskel and colleagues found that ticagrelor-treated mice exhibited marked reductions in lung and liver metastases, which support a role for P2Y12 mediated platelet activation in promoting metastases, and potentially protect against tumor metastasis (19). Similar to TRITON TIMI-38, ticagrelor 
was evaluated against clopidogrel in an ACS population in the PLATO trial, which established ticagrelor's superiority (14). Ticagrelor treatment did not result in an increase of any neoplasm arising during the treatment period. Additionally, there were significantly less benign neoplasms $(0.2 \%$ versus $0.4 \%)$ in ticagrelor users, which contrasts the findings in the PEGASUS-TIMI 54 as stated earlier. With some conflicting results regarding ticagrelor, a retrospective analysis of cancer risk after an ACS according to type of DAPT was conducted. After multivariate analysis, authors found ticagrelor was associated with lower cancer risk than clopidogrel (adjusted HR 0.20; 95\% CI, 0.05-0.84, $\mathrm{P}=0.028$ ), without differences between prasugrel and clopidogrel regardless of DAPT duration (7).

\section{Conclusions}

Despite the alarm of initial findings regarding prolonged treatment with P2Y12 inhibitors, it is unlikely that a significant association exists between cancer diagnosis and patients treated with DAPT. Initial findings in the DAPT trial and others were not powered to detect differences in secondary outcomes, and likely after reviewing several large meta-analyses and cohort studies, that finding may have been a result of unfortunate chance. Perhaps one explanation is due to the many benefits of DAPT; patients are more likely to experience non-cardiovascular death, including malignancy due to prolonged survival. Of the P2Y12 inhibitors, ticagrelor seems to be associated with a lower incidence of de novo cancer during follow-up comparison with prasugrel and clopidogrel, regardless of duration of DAPT. Further studies are needed to confirm any significant difference among P2Y12 inhibitors, but in general, DAPT therapy and its duration should be utilized in accordance with guideline-directed therapy for the respective cardiovascular diseases.

\section{Acknowledgments}

None.

\section{Footnote}

Conflicts of Interest: Dr. Cave discloses that he serves on the speakers bureau of Portola Pharmaceuticals. The other authors have no conflicts of interest to declare.

Ethical Statement: The authors are accountable for all aspects of the work in ensuring that questions related to the accuracy or integrity of any part of the work are appropriately investigated and resolved.

\section{References}

1. Levine GN, Bates ER, Bittl JA, et al. 2016 ACC/ AHA Guideline Focused Update on Duration of Dual Antiplatelet Therapy in Patients With Coronary Artery Disease: A Report of the American College of Cardiology/ American Heart Association Task Force on Clinical Practice Guidelines. J Am Coll Cardiol 2016;68:1082-115.

2. Mauri L, Kereiakes DJ, Yeh RW, et al. Twelve or 30 months of dual antiplatelet therapy after drug-eluting stents. N Engl J Med 2014;371:2155-66.

3. Wiviott SD, Braunwald E, McCabe CH, et al. Prasugrel versus clopidogrel in patients with acute coronary syndromes. N Engl J Med 2007;357:2001-15.

4. Prasugrel and Cancer (Dr. Marciniak). Available online: https://www.accessdata.fda.gov/drugsatfda_docs/ nda/2015/206143Orig1s000MedR.pdf (11 May 2019).

5. Bonaca MP, Bhatt DL, Cohen M, et al. Long-term use of ticagrelor in patients with prior myocardial infarction. $\mathrm{N}$ Engl J Med 2015;372:1791-800.

6. Elwood PC, Gallagher AM, Duthie GG, et al. Aspirin, salicylates, and cancer. Lancet 2009;373:1301-9.

7. Raposeiras-Roubín S, Abu-Assi E, Muñoz-Pousa I, et al. Risk of cancer after an acute coronary syndrome according to the type of P2Y12 inhibitor. Thromb Res 2019;174:51-8.

8. Leader A, Zelikson-Saporta R, Pereg D, et al. The Effect of Combined Aspirin and Clopidogrel Treatment on Cancer Incidence. Am J Med 2017;130:826-32.

9. Bibbins-Domingo K; U.S. Preventive Services Task Force. Aspirin Use for the Primary Prevention of Cardiovascular Disease and Colorectal Cancer: U.S. Preventive Services Task Force Recommendation Statement. Ann Intern Med 2016;164:836-45.

10. FDA Drug Safety Communication: FDA review finds long-term treatment with blood-thinning medicine Plavix (clopidogrel) does not change risk of death. Available online: https://www.fda.gov/Drugs/DrugSafety/ ucm471286.htm (11 May 2019).

11. Roe MT, Cyr DD, Eckart D, et al. Ascertainment, classification, and impact of neoplasm detection during prolonged treatment with dual antiplatelet therapy with prasugrel vs. clopidogrel following acute coronary syndrome. Eur Heart J 2016;37:412-22. 
12. Watters DA, Guest GD, Tangi V, et al. Global Surgery System Strengthening: It Is All About the Right Metrics. Anesth Analg 2018;126:1329-39.

13. Bhatt DL, Fox KA, Hacke W, et al. Clopidogrel and aspirin versus aspirin alone for the prevention of atherothrombotic events. N Engl J Med 2006;354:1706-17.

14. Wallentin L, Becker RC, Budaj A, et al. Ticagrelor versus clopidogrel in patients with acute coronary syndromes. N Engl J Med 2009;361:1045-57.

15. Hicks BM, Murray LJ, Hughes C, et al. Clopidogrel use and cancer-specific mortality: a population-based cohort study of colorectal, breast and prostate cancer patients. Pharmacoepidemiol Drug Saf 2015;24:830-40.

16. Elmariah S, Doros G, Benavente OR, et al. Impact of

Cite this article as: Fierro JJ, Cave B, Khouzam RN. P2Y12 inhibitors: do they increase cancer risk? Ann Transl Med 2019;7(17):409. doi: 10.21037/atm.2019.07.90
Clopidogrel Therapy on Mortality and Cancer in Patients With Cardiovascular and Cerebrovascular Disease: A Patient-Level Meta-Analysis. Circ Cardiovasc Interv 2018;11:e005795.

17. Kotronias RA, Kwok CS, Wong CW, et al. Cancer Event Rate and Mortality with Thienopyridines: A Systematic Review and Meta-Analysis. Drug Saf 2017;40:229-40.

18. Elmariah S, Mauri L, Doros G, et al. Extended duration dual antiplatelet therapy and mortality: a systematic review and meta-analysis. Lancet 2015;385:792-8.

19. Gebremeskel S, LeVatte T, Liwski RS, et al. The reversible P2Y12 inhibitor ticagrelor inhibits metastasis and improves survival in mouse models of cancer. Int J Cancer 2015;136:234-40. 